\title{
THE SOCIOLOGY OF KNOWLEDGE RECONSIDERED
}

\author{
Ernest Manheim \\ University of Missouri, Kansas City
}

The subject of this essay is the communicative function of ideas as a potential determinant of their meanings.

The first proponents of the sociology of knowledge as a field of explorations had a double aim. One - voiced in Marx's writings (1967:372-374) and implied in Max Scheler's and Karl Mannheim's work - was a critical reexamination of the claim of philosophical idealism that social structures are emanations of ideas whose inherent evolution constitutes the medium of continuity in history. This critical aspect of Wissenssoziologie aroused relatively little controversy, particularly in the United States. ${ }^{1}$ The actual debate, whose end is not yet in sight, has centered on the principal aim of Mannheim's Ideology and Utopia, on the attempt to spell out the nature of the relationship between ideas and their existential roots. The literature on the subject may be grouped around three points of view.

The one which stands out in Mannheim's and his disciple's studies is genetic. Mannheim adopted with significant modifications the Marxian thesis that the radius of a person's daily activities (Marx's productive functions) describe the range of his social awareness within which he forms his conception of himself and his milieu, in a manner which is consistent with his aspirations. An inspection will reveal which provinces of the social order have a place in that conception, and which remain concealed. While Marx's pronouncements on ideologies and class consciousness were meant to help "change the world" and not merely interpret it, (1941:84) Mannheim envisaged all ideologies as subjects of non-evaluative and non-promotional inquiries $(1971: 107)$. Their aim was to identify the locus of the social involvement of which a given ideology is the verbal extension. The difficulty which such attempts face stems from the multiple positions and affiliations which individuals maintain in a functionally differentiated society. Some of these affiliations overlap or conflict and become motives of contradictory identifications. Fully aware of these difficulties, Mannheim injected the concept of "intellectual strata" or cognitive systems into his method of procedure. These systems are elaborated points of view which guide the cognitive process and they crystallize around the plural seats of major social aspirations. The locus of these aspirations forms the much discussed existential base. Particular ideologies are derivations from, or modifications of a given cognitive system, but their relationship is relatively indeterminate.

A second type of linkage between ideas and social structures is construed as a quality of congruence between parts of an all-inclusive system thought of as an integrated whole of behavioral and cognitive norms (Sorokin, 1943:80, 87-96). The objective is to identify a problematic item with the system with which it is consistent. The assumption that social structures are traceable to, or emanate from normative principles transcends the scope of sociology and is not susceptible to proof or refutation. 
Finally, the existential basis of ideas is sometimes interpreted functionally, rather than genetically (Merton, 1964:483). Instead of tracing ideologies back to their locus of origin they are weighed and categorized on the strength of their actual or expected consequences. The question here is not what exposures generate a given thought model, but rather how it affects society. Questions of this type set the focus for Durkheim's and Radcliffe-Brown's explanations of rites and beliefs. In a polarized situation in which several contending groups confront one another the question is narrowed to who benefits from a given utterance and whom does it affect adversely. Accordingly, a view is imputed to the faction which is expected to gain by its circulation, regardless whether its members actually embrace that view. "The question whether objective truth can be attributed to human thinking is not a question of theory, but is a practical question" (Marx, 1941:82). Tactical considerations can, therefore, blur or outweigh the interest in the distinction between true or false ideologies, notably when they are judged in an acute conflict situation. Marxian activists were the first to have learned that lesson.

The first and last outlined procedures are designed to illuminate ideas as the dependent pole in a two member relationship. This bipolarity is the product of an abstraction - the isolation of thought contents from the acts which convey them - on the assumption that the communication of ideas is external to their contents and that these are unaffected by the channels through which they reach the recipients. The principal argument of this essay is that a reexamination of that assumption opens up a wider scope for the sociological examination of ideas.

Communication is the habitat of mental products; they are given only in a conveyed form. They are born and conceived as messages to be addressed to real or fancied audiences. The image which the communicator forms of his audience, therefore, affects the contents of his message. The practice of addressing different texts to different audiences does not necessarily evince opportunism or a lacking point of view. The speaker ${ }^{2}$ who faces a new type of audience may well have a new message to convey, and he may adopt new objectives without abandoning an older one. Once ideas are considered not as entities which inhabit a realm of timeless meanings, but as channelled expressions, they come into focus in a four member relationship consisting of (1) the communicator, including his range of social involvements; (2) his message; (3) the channel through which it is communicated; and (4) the actual or intended audience. One may note that the Marx-Scheler-Mannheim paradigm for the sociological identification of ideas rests on the imputation of item $\|_{2} 2$ to item $\|_{1} 1$.

The location of the channel has some bearing on the nature of the message, depending on whether the communicator is in control of the pathways to his audience or, if he has only conditional access to them, who the gatekeepers are. The message varies, moreover, according to whether it is transmitted through internal or external channels. Internal messages reach a selective and homogeneous audience, a consenting "ingroup" which shares the speaker's point of view. External messages are conveyed through unrestricted channels which are accessible to all segments of a heterogeneous audience - the public - 3 including dissenting outgroups.

The effectiveness of communication depends on whether it elicits the intended audience response. Public utterances involving divisive issues tend to maximize their effectiveness by performing three functions: (1) affirm and strengthen the consensus of the speaker's ingroup; (2) sway uncommitted 1isteners; and (3) weaken or undo the accord on which the solidarity of the dissenting outgroup depends. In other words, messages addressed to a heterogeneous, polarized public tend to perform 
more complex functions than are utterances directed internally to a likeminded and consenting audience. Divergent definitions of a common situation may, therefore, originate with the same actor who circulates functionally differentiated messages, and not necessarily with the dissimilar positions of different communicators. An historical episode will illustrate the point in question. It is the case of the rising conservative climate in 18th century Germany.

The original seat of an active traditionalism is traceable to the common indignation of landed noblemen at the erosion of their vested prerogatives. The media through which they voiced such sentiments were the neighborly gatherings of peers and the exchange of letters. It was through these restricted channels that the wish to resist the levelling policy of the central administration and the spreading philosophy of the Enlightenment was articulated.

The support for the dissemination of that suspect philosophy came from the upper ranks of the civil service, at times from the rulers of Prussia, and from a network of fraternal organizations, including Masonic lodges and the "Moral Societies," which sprang up throughout the 18th century. It was in these esoteric gatherings that elements of the middle classes gained contacts with the civil service and, in some instances, the ruling prince.

The first known attempt of the traditionalists to break out of their isolation lead to the infiltration by noblemen of some of the more influential fraternities and the creation of rival sodalities. In both instances the cultivation of intellectual and moral autonomy and its symbols was replaced by a new cult of medievalism in ritual and ideology. Through these pseudo-masonic "orders" the noble participants were able to restore the last channels of influence with members of the central administration. In Prussia they have induced the cabinet to arrest the teaching of rationalistic and libertarian views. These successes were achieved through the use of restricted channels - first the neighborly gatherings and letter exhanges, and subsequently the ritualistic sodalities - but the campaign for a favorable public climate could not be launched without the use of public channels. The disaffected landowners lacked the experience and skills for addressing effectively public audiences, for they were in the habit of speaking only to one another, and they were out of touch with the broader strata of the public.

The literary transmutation of the restorative outlook of the traditionalists into a printable version with some promise of a public appeal was essentially the work of a generation of mobile university graduates of lower middle class background who accepted positions as tutors and secretaries in the households of titled persons. They were in touch with more than one class, conversant with the susceptibilities of various segments of the public, and could write. It was the first generation of the German romantic literary movement which, first through fiction, later by means of printed discourses in social philosophy created a climate for a modified form of the traditionalist ideal. These writers fused concepts to which the Enlightenment gave currency with the reverential treatment of organically evolved conditions, as opposed to bureaucratic reforms and "engineered" institutions; they aroused an interest in things secret and incommunicable, as opposed to the familiar and calculable; and most important, they juxtaposed an idealized image of the past and its surviving remainders with the present pictured as a state of decay. The success of this literary appeal to heterogeneous audiences taught the traditionalists not only to speak a new language and to communicate new ideas, but also to accept those new ideas and to broaden their social base to include elements of the newly founded audiences. It was this 
widened social horizon from which the later conservative rally derived its ideological equipment and its corps of protagonists. The transformation of the traditionalist point of view could not have been deduced from the background of those who brought it about or of those who benefited from it. There seems to be no alternative to the conclusion that the new message was the function of an encounter with new audiences and of a consequently widened social base.

Although the illustrative case sketched in a nutshell derives from an historical episode, it is not a unique instance in which the opening of new channels to new audiences changes the message and self conceptions of the communicator. The phenomenon occurs on the contemporary scene and it is accessible to the sociologist. Observations concerning the audience and the pathways through which it is approached, in addition to the communicator and his message, appear to be the necessary ingredients of the sociological diagnosis of ideas.

\section{Footnotes}

$1_{\text {The occasional flareup of the controversy over the issue of sociological }}$ relativism versus the autonomy of ideas is peripheral to the focus of this essay.

2 The term speaker is used here to denote any agent who addresses a written or verbal message to an audience. The term "audience" is applied to individuals or multitudes to whom messages are channelled through any of the available media - the press, radio, the loudspeaker of the meeting hall, or the conference room.

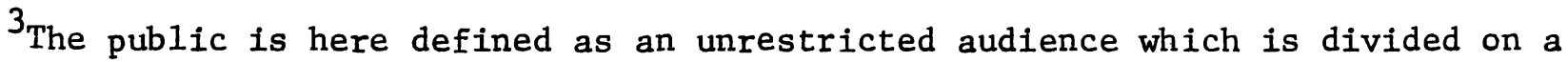
given issue to which a thought complex under study relates.

4

4 The documentation of the following case study is contained in Manheim, 1964: 503-515, and 1933:73-145.

\section{References}

Manheim, Ernest

1933 Die Traeger der oeffentlichen Meinung, Leipzig and Prague: Verlag Rudolf M. Rohrer.

1964 "The communicator and his audience." In Werner J. Cahnman and Alvin Boskoff (eds.), Sociology and History. London: The Free Press.

Mannheim, Kar1

1971 "The problem of a sociology of knowledge." In Kurt M. Wolff, From Karl Mannhe1m. New York: Oxford University Press.

Marx, Kar1

1941 "Thesis on Feuerbach." In Friedrich Engels, Ludwig Feuerbach and the Outcome of Classical German Philosophy. New York: International Pub1ishers.

Merton, Robert $\mathrm{K}$.

1964 "The sociology of knowledge." In Social Theory and Social Structure. London: The Free Press.

Sorokin, Pitirim

1943 Socio-Cultural Causality, Space, Time. Durham, N.C.: Duke University Press. 